\title{
Causarum Cognitio, O Conhecimento das Causas a Escola de Rafael Sanzio
}

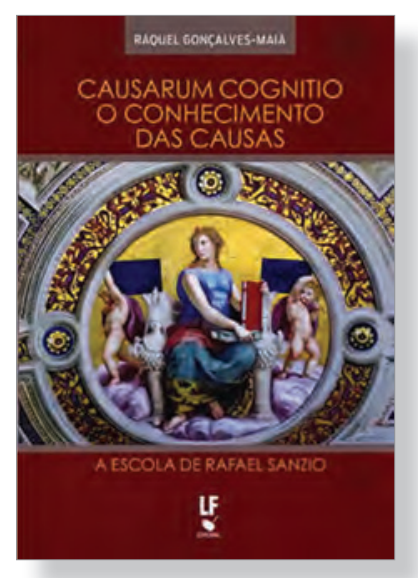

\author{
Autor: Raquel Gonçalves-Maia \\ Editora: Livraria da Física (São Paulo) \\ N. ${ }^{\circ}$ de Páginas: 208 \\ ISBN: 978-85-7861-310-5
}

Risoleta C. Pinto Pedro

(Escritora)

\section{Raquel, Rafael, a “Escola” e as Escolas \\ (Resumo de uma viagem a Atenas \\ com regresso a Portugal, sem de cá ou de lá sairmos)}

Raquel Gonçalves-Maia, cientista, divulgadora de ciência, tem feito numerosas e importantes pontes entre ciência, arte, símbolo e ficção. É um espírito veloz, curioso, insaciável, e tem tanto de tranquilo como de inquieto. Escreve agora sobre “A Escola de Atenas”, de Rafael Sanzio, olhar livre e despreconceituoso da cientista sobre a arte, a filosofia e a história. Num colo de ciência, um olhar científico, estético e simbólico. Recomendo-o porque ensina, abre horizontes, interroga, expande, espanta-se, assombra-nos e indicia. Numa linguagem bela.

Quem está no centro deste livro que analisa a pintura onde foram reunidos génios do pensamento desde o século VII antes de Cristo ao século XVI depois de Cristo? Aristóteles? Platão? Sócrates? Os Sofistas? Rafael Sanzio? A Pintura? A Filosofia? A História? A Ciência? Ou Averróis? Ou o Papa Júlio II? Ou...? Vários são os centros e todos se encontram, como no mundo das ondas. Da filosofia antiga à ciência moderna, passando pela eterna estética, pela eterna poética.

Entramos com Raquel na pintura e não sabemos aonde a viagem nos conduzirá. Que existe do outro lado da tela? Não é de menosprezar a figura de convite que é a epígrafe, e que dá o tom, pelas palavras de Agostinho:

"Espero que um dia olhemos a serpente e a vejamos oculta; que a Ciência e a Filosofia sejam, no presente, um sonho do passado e que o mesmo aconteça com a Arte e com a Religião."

\section{Agostinho da Silva}

Acrescento: Que o mesmo aconteça com a Escola, como Rafael a pinta, como a viveram os atenienses e como continuaram a vivê-la alguns filósofos... portugueses:

"Afastados do ensino oficial, dispensados de compromissos com as normas legais de validação do ensino, [...] os dois amigos [Álvaro Ribeiro e José Marinho] criaram uma escola de filosofia que é certamente das mais notáveis actualizações da livre docência dos grandes mestres atenienses. [...] Unidos pelo amor da sabedoria, mestres e discípulos exercitaram aquela ascese intelectual que José Marinho com propriedade designou de anagogia."

In: Filosofia Portuguesa para a Educação Nacional, Joaquim Domingues

Acompanhemos então esta cientista também escritora e experimentemos a sua escrita analítica, poética, rigorosa e elegante.

Platão e Aristóteles são, inequívoca, especial e espacialmente, as figuras centrais, dois dos guias por onde entraremos no labirinto das infinitas possibilidades da arte, "as respostas nunca definitivas”.

A magia dos números compõe o quadro da complexidade: "nesta composição grandiosa (7,7 m de comprimento por 5,5 m de altura)”. O método científico aqui aplicado à arte não afugenta o mistério.

Rafael, que com onze anos de idade já administrava os conflitos familiares, precoce diplomata dos matizes emocionais, filho de mãe chamada Magia precocemente perdida, é, ao contrário dos costumes da época, alimentado junto ao coração. Como precioso passarinho bebendo o leite alado. Para voar.

Entretanto, cresce. Conhece Leonardo. Admira-o. Espelha, nas feições de Platão, o rosto de Leonardo. Assiste à luta dos titãs Leonardo e Michelangelo. É chamado para Roma, pelo Papa. O sonho do pintor que, sem o desejar, mas por causa do seu talento, foi responsável por o papa ter despedido todos os outros ao seu serviço.

A partir da pintura, a análise aprofundada ao pormenor. Não para arquivar em gavetas de laboratório, mas para procurar os paradoxos, as possíveis contradições. O estilo é vivo e caloroso, como ela própria: "Vazio? Que horror!" Que longe está a fria antiga pedra científica do laboratório! 
A viagem é a Atenas em tempo de outra troika, de onde e da qual recebemos quase tudo, trio amoroso e insuspeito, sábio e não assustador, inquieto, não inquietante, com "Sócrates, o «Sábio», Platão, o «Mestre», e Aristóteles, o «Professor» [..] membros desta ilustre trindade". Afinal não é troika, segundo Raquel é Trindade (a maiúscula é minha, a cientista não me perdoaria a corrupção) e é fácil encontrá-la: na "Escola" de Rafael. O guia é o extraordinário livro de Raquel, guia ciencioartística da intemporalidade.

Recomendo colocar em cada casa este livro de Raquel sobre Rafael e a história da Filosofia clássica, que é berço da nossa, embora não obrigatoriamente "condição” ou “destino" (sobre isto recomendo muito a leitura de O Céu e o Quadrante, de Pedro Martins,) e adormecermos todas as noites embalados pela Escola de Atenas. A sonhar com a Nossa. Aquela que, levantando-se da sombra, ainda se encontra semi-oculta, mas brilhou, por momentos, na Universidade de Leonardo Coimbra e nas tertúlias: selva, casas, montanha, naus, ruas e cafés. Com ele próprio, Leonardo, com Sampaio Bruno, com Álvaro Ribeiro, com Pascoaes, com Fernando Pessoa, com Agostinho da Silva, com José Marinho, com Delfim Santos, com António Quadros, com Afonso Botelho, com António Telmo, e outros...

Falta-nos Rafael, ou um pintor como ele, que os junte e os ponha a falar para nós ouvirmos, que projecte o som através dos tempos a ponto de ser ouvido por uma cientista apaixonada por história, filosofia e arte e que sobre eles escreva e transcreva, com tecnologia de ponta, os diálogos que tiveram e até mesmo os pensamentos que repeliram. Um pintor inspirado e documental que pinte a Escola de Lisboa, a do Porto, a de Brasília, a de Sesimbra, a de Estremoz... E que, como Rafael e Raquel, lhes dê movimento e som.

Neste livro-altar em templo de arte, realiza-se casamento e diálogo de duas histórias: a da Filosofia e a da Ciência, bem como a influência espiritual exercida pelos professores. Essa influência espirital dos professores está igualmente numa página de Joaquim Domingues a propósito de Álvaro Ribeiro (a já acima citada Filosofia Portuguesa para a Educação Nacional), evocando o importante mestrado e convívio do mestre (Leonardo Coimbra) com o discípulo (Álvaro Ribeiro), depois tornado mestre de mestres.

“[...] como as formas superiores de docência se distinguem do que habitualmente se pensa da relação professor-aluno, aproximando Leonardo dos mestres atenienses [...]” (sublinhado meu).

\section{E retomo:}

“Sem cair em fáceis antinomias, opondo o que é complexo, há-de entender-se aqui como mestre o que abre a inteligência para níveis superiores de compreensão, numa relação que envolve uma dimensão sagrada, sacerdotal ou secreta: «O mestre é senhor de segredos que só revelará aos iniciandos e iniciados. Situado no seu quadro sacerdotal, Pitágoras figura evidentemente como o precursor de Platão, filósofo capaz de ver para além do visível.»

Assim, os mestres da Renascença Portuguesa reactualizaram uma tradição interrompida ou esquecida desde há muito...”
Diz ainda Joaquim Domingues, a propósito de Álvaro Ribeiro (que é, segundo António Telmo, o formador da Filosofia Portuguesa - de Sampaio Bruno teria vindo a emanação, para Pedro Martins, fundação, e de Leonardo Coimbra a criação): "acima de tudo, foram as tertúlias filosóficas que lhe ofereceram a cátedra mais eficaz e fecunda.”

É a tertúlia filosófica que Raquel mostra e que aprendemos dos gregos, que tem sustentado a Filosofia Portuguesa.

A Escola da Filosofia Portuguesa, que não se pode separar do estudo da Língua, da Poesia e da Gramática, nasce com um rei poeta, o maior dos primeiros, o mesmo que fixou a língua para além da fala. Com este rei, a sua medida administrativa e sua poesia, nasce a nossa tradição filosófica e poética da saudade. Isto está magnificamente demonstrado por Pedro Martins, no livro já acima referido, O Céu e o Quadrante, em que explica de que forma a Filosofia Portuguesa reune a Poética e o Pensamento num abraço saudoso e profundo. Os poetas e os intelectuais abraçam-se.

O caminho que aqui nos conduziu chama-se $O$ Conhecimento das Causas e é incontornável para quem pretenda conhecer ou esclarecer-se sobre "as correntes filosóficas" e os “avanços científicos” na “Antiguidade, mas também no período Medieval e Renascentista”.

O que me levou a reunir o livro de Raquel Gonçalves-Maia e “A Escola da Filosofia Portuguesa” num mesmo texto é esta mesma sensibilidade à tradição do pensamento que pode encontrar-se inequivocamente no seu livro e nos Filósofos Portugueses que aqui referi, nomeadamente, num pequeno grande livro de Álvaro Ribeiro que recomendo (com sorte talvez consigam encontrá-lo em algum alfarrabista): $O$ Problema da Filosofia Portuguesa: "não é de filosofia em Portugal, mas de Filosofia Portuguesa que a nossa cultura verdadeiramente carece; [...] Tudo depende [...] de recomeçar uma tradição [...] que venha a formular, em sistema ou sistemas, a filosofia própria da fisionomia nacional.”

Já terminara a escrita desta recensão ou testemunho da reflexão da minha alma, quando, relendo o que escrevera, um raio de sol da meia-noite me soprou ao ouvido a lembrança de que António Telmo, uma das mais eloquentes e recentes vozes da Filosofia Portuguesa, afirma, em Filosofia e Kabbalah, que em Aidós ou no Hades, a sombra de Platão e Aristóteles reflete a imagem pintada por Rafael. Atrás deste fio de luz veio à minha memória a lembrança vaga do conto "No Hades" inserido no livro acima referido, onde o protagonista chega a subir os quatro degraus que lhe permitiriam ver e ouvir, no que parecia ser uma imagem bidimensional, o movimento, as falas, a vida tal como a conhecemos.

É a essa mesma vida que Raquel Gonçalves-Maia, pelo método científico temperado de Graça, acede e nos convida.

Já era tarde qando concluí este texto, mas o bichinho já tinha entrado, estava instalado e não resisti a ir lá, a António Telmo, apresentar-lhe Raquel. E vice-versa. Ouçamos, então, António Telmo, em diálogo com Raquel Gonçalves-Maia. Aqui vos apresento Filosofia Portuguesa e Ciência em diálogo, no seu melhor, no seu nível mais alto, unidas pela Ética e pela Poética, diálogo santo entre o Hades e o Gerês: 


\section{Começa Telmo:}

"Não ouvíamos o que diziam [Platão e Aristóteles] porque nada diziam que se ouvisse cá em baixo. [...] pela disposição desses livros e pela disposição das mãos que as duas sombras estavam uma para a outra na exacta relação ritual do esquadro e do compasso. [...]

O que ali me aparecia era o símbolo do perfeito entendimento entre os dois filósofos. Eles conduziam e projectavam na nossa direcção a mesma energia urânica, um recebendo-a, pelo dedo em ponta, na mão fechada e passando-a para o outro que a dirige para nós pelos dedos separados da mão de palma voltada para a terra. Os olhos nos olhos concentram num único ponto o foco interior dessa energia. [...] Procurava as ocasiões [...] para me pôr diante das imagens dos dois filósofos, como se, de um momento para o outro, os pudesse ouvir falar. Tinha, porém, a certeza íntima que isso só aconteceria se conseguisse lançar-me fora de mim e subir aqueles quatro degraus. [...]

O famoso pormenor do fresco de Rafael com os dois filósofos estava na parede do fundo. Como era possível que ainda não tivesse reparado nisso? Mas logo que baixei o braço para continuar a vê-lo, apareceu-me o fundo da sala envolto numa espessa obscuridade, [...]

«Não pense que teve uma visão. A pintura está lá, isto é, uma reprodução a cores. A sua percepção tornou-se mais subtil. É só isso! Venha ver!»

De facto, na parede do fundo lá estava um quadro reproduzindo o pormenor do fresco com os dois filósofos. [...]

«Tomando à letra o que você me diz, não nos devemos admirar se, a nosso rogo, Platão nos entregar o seu Timeu ou Aristóteles as suas Categorias. Estou-me a ver a levá-los para casa, a folheá-los na minha secretária.»

Tomé Natanael ficou muito sério.

«Observe bem a pintura.» [...] Se estudar as categorias e souber estabelecer as suas exactas relações, poderá determinar a estrutura oculta da composição de Rafael. Conhecerá o que são os quatro degraus, as duas colunas humanas, o pórtico. De nada vale bater à porta da vida sem bater ao mesmo tempo à porta do espírito. [...]

Tomé Natanael, depois de ter lido os apontamentos, não disse uma palavra. [...] Quem entrasse pela porta ver-nos-ia aos dois, nas nossas roupas cinzentas, direitos e de braços pendentes, como dois candelabros de estanho. Eu sentia aquele momento como uma espécie de oração silenciosa $[\ldots]$

Somente por uma demorada acção sobre si próprio no domínio da imaginação poética é possível ao homem adquirir a virtude régia que lhe permita passar o grande abismo [...]”

“No Hades”, in Filosofia e Kabbalah, António Telmo

Responde Raquel:

“As expressões das figuras [...] deixam transparecer o seu carácter psicológico. Rafael notabilizou de forma sulime o conhecimento natural do mundo, isto é, o conhecimento dos homens. [...] estamos perante uma cena de teatro duma narrativa em movimento [...] Quase podemos adivinhar os diálogos entre os elementos de cada grupo, quiçá neles participar, ou, simplesmente, atinar com os pensamentos que afetam os homens isolados. Por que corre uma das personagens para o palco, entrando à esquerda com um rolo e dois livros debaixo do braço? Por que se esgueira outra, à direita, em passo apressado na mesma linha horizontal? Serão elas imagens do tempo com passado, com futuro e com presente fugaz? [...] Perto de nós, o múltiplo quadriculado do chão de “A Escola de Atenas”, símbolo da Terra, antítese do transcendente, bem pode resumir a captação do instante do homem encarnado.

[...] é bem possível que Rafael Sanzio [...] acreditasse que o curso da humanidade estivesse inscrito, desde o início dos tempos, num plano secreto e arquitectado por Deus, e que o conhecimento pesquisado pelo homem fosse alcançado por inspiração divina. 'A Escola de Atenas' foi o seu meio grandioso e encantador de mostrar ao mundo a descoberta do homem.

[...] O legado da Grécia e de Roma para a cultura ocidental flosófica e científica merecia, é um facto, uma homenagem desta dimensão. A 'leitura’ da magnífica obra de Rafael Sanzio é fascinante. Que importa que o século XII espreite sobre o ombro do século VI a.C., se aquele mais deseja aprender sobre a perfeição dos números melódicos? Nada de intrigante que uma acesa discussão, reveladora do Universo e da Terra, tenha lugar entre um mancebo do século VII a.C e outro do século II, e para mais, atentamente escutada por pintores renascentistas..."

Causarum Cognitio, O Conhecimento das Causas; Raquel Gonçalves-Maia

O que aqui me apareceu foi “o símbolo do perfeito entendimento” entre um filósofo e uma cientista.

“Nada de intrigante” que o filósofo tenha partido em 2010 para o Hades ou para uma planície ou montanha de luz e a cientista esteja hoje no Gerês ou em Braga, em plena era de abençoada criação e vitalidade, a prometer mais, muito mais, como há anos, ininterruptamente, lhe conheço.

Paz na Terra e Glória nos Céus aos Seres de uma Escola ou Academia de Boa Vontade e Amor pela Verdade. Na interrogação e no espanto.

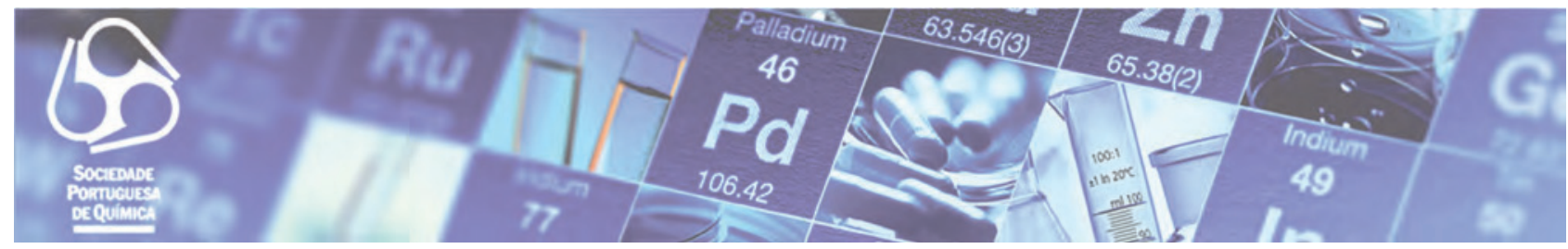

